\title{
Selection of Access Network using Cost Function Technique in Heterogenous Network
}

\author{
Abdullah H. Al-Ghushami ${ }^{1}$, Abdulghani Ali Ahmed ${ }^{2}$ \\ ${ }^{1}$ IT Department, Community college of Qatar, 7876 alsada Doha, Qatar \\ ${ }^{2}$ Safecyber Systems Private Limited
}

\begin{abstract}
.
the challenge for future generation of wireless environment is on how to choose the appropriate wireless access network connection when there are several different wireless networks. Hence, there are many available handover methods, which depend on a single parameter like RSS method. These methods did not use the advantages of multi network parameters and do not take into consideration the quality of service of ongoing session to increase user satisfaction based on their preferences. A vertical handover network selection (VHNOS) method is being used to aid in term of service quality for the user satisfactions of the mobile terminals. This study intends to propose the method of choosing the vertical handover network selection. This method adopted the cost function, and also covers the weight distribution and cost factor techniques. The weight distribution is used to measure different weights for existing wireless network based on the user preference and mobile terminal power. The cost factor technique is also being used to identify the cost for performing handover target by considering every network parameters and its weight. Results obtained showed that this algorithm has the ability to increase user satisfaction compared to the other algorithms, which consistently choose single accessible network.
\end{abstract}

Keywords - Heterogeneous Wireless Networks, Network Selection, Cost Function, Weight Distribution, VHONS, Vertical Handover. 


\section{INTRODUCTION}

Mobile device subscriptions are continually rising in the whole world. According to a study by The International Telecommunication Union (ITU) [1], the convergence of mobile devices and wireless communication systems have significantly driving the changes in people's everyday life. People are bringing their mobile devices everywhere and every time for work purposes.

The increase of mobile terminals requires a heterogeneous wireless network to access network resources effectively. In a wireless environment, the MTs will have several networking interfaces in order to access different type of networks. Such mobile terminals did not only support network access and suitable connection flexibility, but also support the mobility between other networks. MT may expect uninterrupted and continuous network when users are moving from a network to another network. The process which nearly prevents interruption in a network environment is being called as vertical handover (VHO)[2].

The Handover is the process of changing and switching the mobile terminals from one wireless network to another [3][4]. Handover has two different types - horizontal and vertical. Horizontal handoff (HHO) occurs among same network technologies (i.e: HHO) occurs among two BSs). On the other hand, vertical handoff (VHO) happens between different network technologies, for instance, it happens between access point (AP) and base station [4][5] . Below is an example of horizontal or vertical handoff as shown in Figure 1.



Figure 1.

Vertical vs Horizontal Handover

VHO is classified into two types which are upward VHO and downward VHO [5]. The upward VHO occurred when it moves from a small coverage with huge data rate to a bigger coverage but with lesser data rate network. For the downward VHO, it takes place in the opposite way. Here is an example of vertical handoff as shown in Figure 3, show that Vertical handoff happens 


\section{SCIENCE, ENGINEERING \& TECHNOLOGY}

between different network technologies, for instance, between WLAN network, cellular 2019 network (3G) network and WiMAX network.



Figure 2. Example Of Vertical Handover Mechansim

Here is an example of horizontal handoff as shown in Figure 6, show that horizontal handoff happens between same network technologies, for instance, between two cellular(3G) wireless networks.

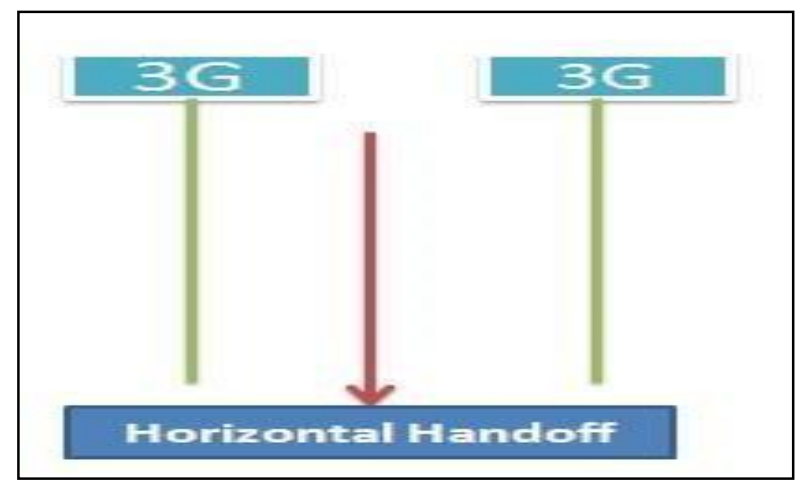

Figure 3. Example of Horizontal Handover Machanism

\section{A. Vertical Handover Process}

The VHO process is required in order to select the finest wireless network. It must evaluate the information which belongs to mobile devices and its capabilities. Besides that, it will assess the application requirement in terms of service quality and user preferences to decide whether the handover could be continued. Moreover, this process has been commonly included in three major phases which are system or network discovery, handoff decision and execution or triggering [11]. These phases are shown in figure 7 below: 


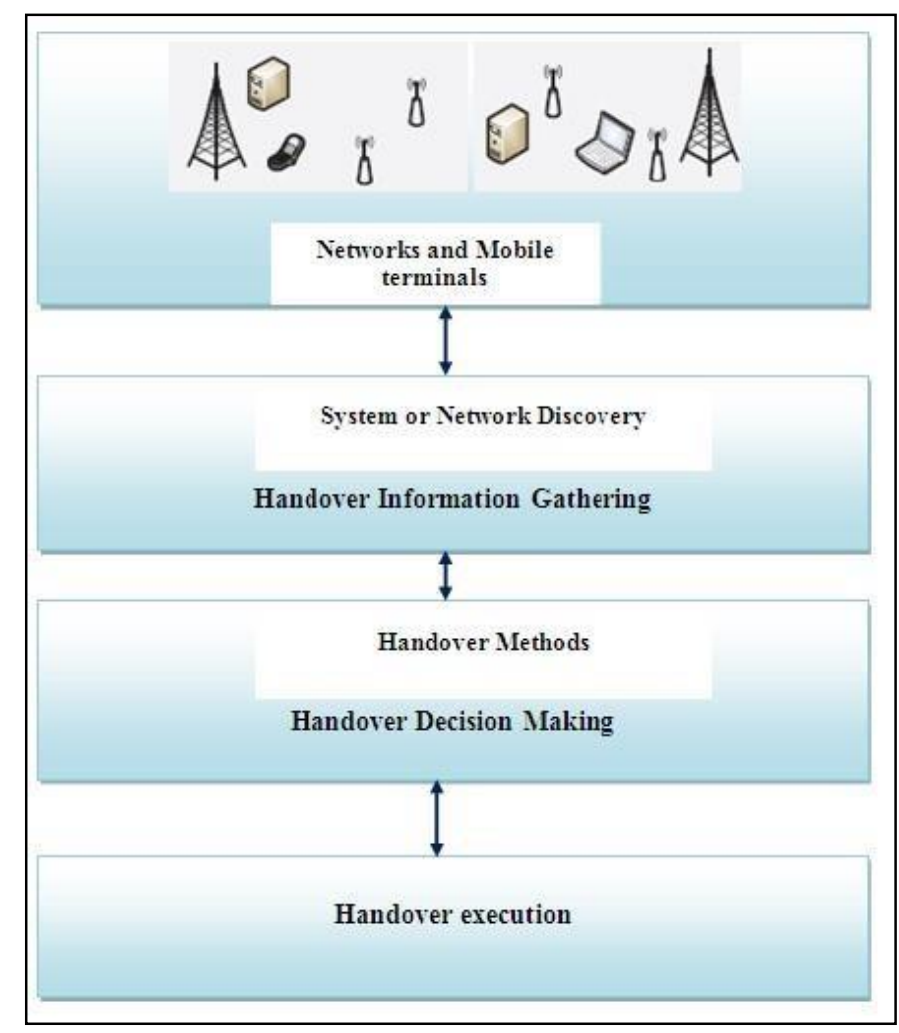

Figure 4. VHO Process

Next section explains the parameters for vertical handover and the VHO process, continued with section III that describes the VHO decision methods. Then Section VI presents our proposed vertical handover network selection method which is being adopted on cost function approach. Lastly, section IV focuses on the simulations and results, followed with the conclusion.

\section{PARAMETERS FOR VERTICAL HANDOVER}

Various parameters being suggested in the literature [7, 8, 9] in using the process of VHOD. Commonly, by using various parameters, it is useful to avoid the wrong handover decisions[6].The brief explanation shown below:- 


\section{A. Bandwidth}

It is to measure how much data the communication could send over specific connection, which is represented in bit per second. It is an important criterion to decide and select a suitable wireless network.

\section{B. Received Signal Strength (RSS)}

It is used to identify the quality of service. It is also an important parameter for VHD algorithms, but it is not yet sufficient to directly complete the decision.

C. Power

It is a common issue when dealing with mobile devices since the power run off quickly. In such situation, it is suggested to search for any network access that could extend the life of battery power.

\section{User Preferences}

After the handover, users can access a type of network over another candidate. It means, users will have many choices in heterogeneous networks with their preferences.

\section{E. Cost}

The cost value for different wireless networks is charged based on various policies. Thus, in many situations, the cost of the services need to take into consideration in triggering handoff decision.

F. delay

It denotes elapse times for mobile terminals after handoff decisions occurred.

\section{G. Security}

This is to ensure the confidentiality of the transmitted information. A network with good protect system will be selected among other network, that offers weak security system.

\section{H. Network Condition}

This is a network related criteria like network traffic, existing bandwidth. It has been taken into consideration in order to have an efficient and effective network usage

\section{Network Performance}

It is used in order to guarantee a good condition of the network/system performance,

The VHO process is used to choose the best wireless network. Moreover, this process commonly included in three major phases which are system or network discovery, handoff decision and execution or triggering [10]. a) Network discovery phase

It is a process to gather all information which are required, in order to discover the needs for handoff. It is also a process where MTs search for wireless networks. b) Handover decision phase 
It helps to decide when and how to occure a handover, by choosing a appropriate wireless network (by taking into consideration some parameters). The proposed method will be achieved in this phase.

\section{c) Handover execution phase}

It is the final step or phase within any handover procedure when the MTs transfer from one network to a new network.

\section{VHO DECISION METHODS}

This section discusses about the existing VHO methods which were proposed to solve VHO decision challenges Thus, Among the available VHO decision algorithms are user centric method, context aware method, fuzzy logic and also cost function were applied [11]. Various studies have conducted regarding the cost function method.

But, there are many available handover methods, which depend on a single parameter like RSS method. These methods did not use the advantages of multi parameters [6]. But, the VHO network selection problem can be addressed by considering the cost function method.

Cost function algorithm contains the parameters such as, bandwidth and many more. The VHO method is concern on the cost function that usually calculate the "cost" of suitable target wireless networks [12,13]. The lowest cost network will be selected. This will increase the user's satisfaction. However, they did not discuss on how the quality of service parameters were normalized or how weight parameters being assigned $[12,13]$.

It is suggested to apply a cost function method on which normalized and weight distributions approaches being offered [14]. However, some criteria such as security is hard to be estimated [14]. A previous study shows weight function based VHO decision method, which is used to delegate the VHO calculation for visiting wireless networks instead of mobile user nodes [15].

\section{PROPOSED METHOD}

The vertical handover network selection approach is proposed to maximize and increase the user satisfaction by finding and selecting the most efficient wireless network to perform a handover between different wireless networks. The VHONS approach has adopted the cost function method and has selected a network with the lowest cost to be handed over to the target. It includes two approaches, which are Weight Distribution (WD) and Cost Factor Calculation (CFC). a) Weight distribution

It is processed to gather user preference, while the mobile terminal power acted as the input information. It produces weight factors of several VHO decision parameters as the output information. The preference specified by the user for the network criteria includes bandwidth, cost security, delay, network performance and network condition. The network criteria level is 


\section{SCIENCE, ENGINEERING \& TECHNOLOGY}

being classified as high, medium, low and none. It is used to identify weight factors of 2019 bandwidth, cost, security, delay, network performance, network condition and power by applying the approach shown below.

The main aim to calculate $W_{B}, W_{M}, W_{S}, W_{D}, W_{F}, W_{C O}$ and $W_{\mathrm{P}}$ preferences and power

of the battery, that is indicated as the input information. The equations obtained are as follows:

$$
\begin{aligned}
& \mathrm{n}_{\mathrm{B}} \times \mathrm{w}_{\mathrm{B}}+\mathrm{n}_{\mathrm{M}} \times \mathrm{w}_{\mathrm{M}}+\mathrm{n}_{\mathrm{S}} \times \mathrm{w}_{\mathrm{S}}+\mathrm{n}_{\mathrm{D}} \times \mathrm{w}_{\mathrm{D}}+ \\
& \mathrm{n}_{\mathrm{F}} \times \mathrm{w}_{\mathrm{F}}+\mathrm{n}_{\mathrm{P}} \times \mathrm{w}_{\mathrm{P}}+\mathrm{n}_{\mathrm{CO}} \times \mathrm{w}_{\mathrm{CO}}=\mathrm{P}_{\mathrm{w}}
\end{aligned}
$$

Next, the weight being calculated by

equations which is shown below:-

$w_{P}=0$

$$
\begin{aligned}
& \mathrm{w}_{\mathrm{B}}=\frac{\mathrm{i}_{\mathrm{B}} \times \mathrm{P}_{\mathrm{W}}}{\mathrm{n}_{\mathrm{B}} \times \mathrm{i}_{\mathrm{B}}+\mathrm{n}_{\mathrm{M}} \times \mathrm{i}_{\mathrm{M}}+\mathrm{n}_{\mathrm{S}} \times \mathrm{i}_{\mathrm{S}}+\mathrm{n}_{\mathrm{P}} \times \mathrm{i}_{\mathrm{P}}+\mathrm{n}_{\mathrm{D}} \times \mathrm{i}_{\mathrm{D}}+\mathrm{n}_{\mathrm{F}} \times \mathrm{i}_{\mathrm{F}}+\mathrm{n}_{\mathrm{CO}} \times \mathrm{i}_{\mathrm{CO}}} \\
& \mathrm{w}_{\mathrm{M}}=\frac{\mathrm{i}_{\mathrm{M} \times \mathrm{P}_{\mathrm{W}}}}{\mathrm{n}_{\mathrm{B}} \times \mathrm{i}_{\mathrm{B}}+\mathrm{n}_{\mathrm{M}} \times \mathrm{i}_{\mathrm{M}}+\mathrm{n}_{\mathrm{S}} \times \mathrm{i}_{\mathrm{S}}+\mathrm{n}_{\mathrm{P}} \times \mathrm{i}_{\mathrm{P}}+\mathrm{n}_{\mathrm{D}} \times \mathrm{i}_{\mathrm{D}}+\mathrm{n}_{\mathrm{F}} \times \mathrm{i}_{\mathrm{F}}+\mathrm{n}_{\mathrm{CO}} \times \mathrm{i}_{\mathrm{CO}}} \\
& w_{S}=\frac{i_{S} \times P_{W}}{n_{B} \times i_{B}+n_{M} \times i_{M}+n_{S} \times i_{S}+n_{P} \times i_{P}+n_{D} \times i_{D}+n_{F} \times i_{F}+n_{C O} \times i_{C O}} \\
& w_{D}=\frac{i_{D} \times P_{W}}{n_{B} \times i_{B}+n_{M} \times i_{M}+n_{S} \times i_{S}+n_{P} \times i_{P}+n_{D} \times i_{D}+n_{F} \times i_{F}+n_{C O} \times i_{C O}} \\
& \mathrm{w}_{\mathrm{F}}=\frac{\mathrm{i}_{\mathrm{F}} \times \mathrm{P}_{\mathrm{W}}}{\mathrm{n}_{\mathrm{B}} \times \mathrm{i}_{\mathrm{B}}+\mathrm{n}_{\mathrm{M}} \times \mathrm{i}_{\mathrm{M}}+\mathrm{n}_{\mathrm{S}} \times \mathrm{i}_{\mathrm{S}}+\mathrm{n}_{\mathrm{P}} \times \mathrm{i}_{\mathrm{P}}+\mathrm{n}_{\mathrm{D}} \times \mathrm{i}_{\mathrm{D}}+\mathrm{n}_{\mathrm{F}} \times \mathrm{i}_{\mathrm{F}}+\mathrm{n}_{\mathrm{CO}} \times \mathrm{i}_{\mathrm{CO}}} \\
& \mathrm{w}_{\mathrm{CO}}=\frac{\mathrm{i}_{\mathrm{CO} \times \mathrm{P}_{\mathrm{W}}}}{\mathrm{n}_{\mathrm{B}} \times \mathrm{i}_{\mathrm{B}}+\mathrm{n}_{\mathrm{M}} \times \mathrm{i}_{\mathrm{M}}+\mathrm{n}_{\mathrm{S}} \times \mathrm{i}_{\mathrm{S}}+\mathrm{n}_{\mathrm{P}} \times \mathrm{i}_{\mathrm{P}}+\mathrm{n}_{\mathrm{D}} \times \mathrm{i}_{\mathrm{D}}+\mathrm{n}_{\mathrm{F}} \times \mathrm{i}_{\mathrm{F}}+\mathrm{n}_{\mathrm{CO}} \times \mathrm{i}_{\mathrm{CO}}}(7)
\end{aligned}
$$

(8)

In the above equation, the mobile system has the ability to allocate weights to network criteria based on user's preference and Pw.

b) Cost factor

Cost factor calculation approach is to estimate and calculate the rate for performing handover to each target wireless network via cost function. It is administered to gather several network criteria and it is being weighted as input data, and will yield the cost of the whole target wireless networks. Cost factor $\left(C_{i}\right)$ that offers measurement for network (i) cost, is evaluated by using function as shown below:



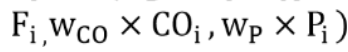

(9)

$C_{i}$ indicates the cost equations, while $B_{i}, M_{i}, S_{i} D_{i}, F_{i}, C O_{i}$ and $P_{i}, \quad$ represent the bandwidth [Mpbs], cost 
(cents/rails), security scale (in a scale from 1 to 10), delay (in ms), network performance (in \%), network condition (in scale of 1 to 10 ) and power (in scale of 1 to 10 ), and $w_{B}, w_{M}, w_{S}, w_{D}$, $W_{F}, W c o$ and $W_{P}$ are the weights taken from the weight distribution $\left(\mathrm{W}_{\mathrm{D}}\right)$ method.As every network parameter or criteria have a diverse unity, it is in need to be normalized in term of cost function. Normalization of the cost is:

$$
\begin{aligned}
& \mathrm{C}_{\mathrm{i}}=\frac{\mathrm{w}_{\mathrm{B}} \times\left(1 / \mathrm{B}_{\mathrm{i}}\right)}{\max \left(1, / \mathrm{B}_{\mathrm{i}}\right)}+\frac{\mathrm{w}_{\mathrm{M}} \times \mathrm{M}_{\mathrm{i}}}{\max \left(\mathrm{M}_{\mathrm{i}}\right)}+\frac{\mathrm{w}_{\mathrm{S}} \times\left(1 / \mathrm{S}_{\mathrm{i}}\right)}{\max \left(1 / \mathrm{S}_{\mathrm{i}}\right)}+\frac{\mathrm{w}_{\mathrm{D}} \times\left(1 / \mathrm{D}_{\mathrm{i}}\right)}{\max \left(1, / \mathrm{D}_{\mathrm{i}}\right)}+ \\
& \frac{\mathrm{W}_{\mathrm{F}} \times\left(1, / \mathrm{F}_{\mathrm{i}}\right)}{\max \left(1 / \mathrm{F}_{\mathrm{i}}\right)}+\frac{\mathrm{W}_{\mathrm{CO}} \times\left(1 / \mathrm{C} \mathrm{CO}_{\mathrm{i}}\right)}{\max \left(1, / \mathrm{CO}_{\mathrm{i}}\right)}+\frac{\mathrm{W}_{\mathrm{P}} \times \mathrm{P}_{\mathrm{i}}}{\max \left(\mathrm{P}_{\mathrm{i}}\right)}
\end{aligned}
$$

Finally, the wireless network with lowest cost $(\mathrm{C} 1 \ldots . . \mathrm{Cn})$ will be chosen as the handover target wireless network. This algorithm shows the performance of the simulation and the result section.

The proposed method for vertical handover wireless network selection decision is shown in the steps below:

1) WD combined users preferences and Pw generates weight for several VHOD parameters.

2) VHONS listed all existing candidates of wireless networks by using random arrangement.

3) Initiating wireless network with the candidates by using utmost priority and the wireless network parameters are collected for VHO decision.

4) The cost factor being calculated by using parameters which is combined in phase three and the cost function.

5) The vertical handover selection test did if there is any network candidates left. If yes, it is required to be processed again in phase three; if not, then that is the end. 6) The lowest cost network is chosen to perform handover

V. SIMULATION AND RESULT Matlab simulation tools was used for evaluating a performance of suggested/proposed algorithm. The results are as shown and discussed in this section. There is also comparison with other methods.

The equation to calculate user's satisfactions as follow:-

TABLE I. WIRELESS NETWORK PARAMETERS FOR PERFORMANCE EVALUATION OF VHONS 
2nd International Conference on Research in

SCIENCE, ENGINEERING \& TECHNOLOGY

Oxford, United Kingdom

\begin{tabular}{|c|c|c|c|}
\hline $\begin{array}{c}\text { Wireless } \\
\text { Network No. }\end{array}$ & 1 & 2 & 3 \\
\hline Kind & WiMAX & WLAN & $\begin{array}{l}\text { UMTS } \\
(3 \mathrm{G})\end{array}$ \\
\hline Bandwidth & $2000 \mathrm{kbps}$ & $1000 \mathrm{kbps}$ & $384 \mathrm{kbps}$ \\
\hline Cost & 3 cents $/ \mathrm{min}$ & 2 cents/min & 5 cents $/ \mathrm{min}$ \\
\hline Security & 1 & 2 & 7 \\
\hline Delay & $30 \mathrm{~ms}$ & $20 \mathrm{~ms}$ & $90 \mathrm{~ms}$ \\
\hline Network Condition & 50 & 60 & 70 \\
\hline $\begin{array}{l}\text { Network } \\
\text { Performance }\end{array}$ & 80 & 90 & 100 \\
\hline Power & 3 & 2 & 1 \\
\hline
\end{tabular}

During the performance evaluation, there are three wireless networks being as candidates, involving WLAN, UMTS (3G), WIMAX as presented in the table II above.

The MATLAB simulation was used for generating one thousand sets of user preference bandwidth (B), cost (M), security (S), delay (D), network performance (F) and network condition $(\mathrm{CO})$ in random. The performance criteria which is the user satisfaction, has been adopted in order to compare the result of choosing only single wireless network with the use of VHONS.

The user satisfaction has been identified by changing the approach [14], adding additional criteria and weights. The user satisfaction equation is shown below:

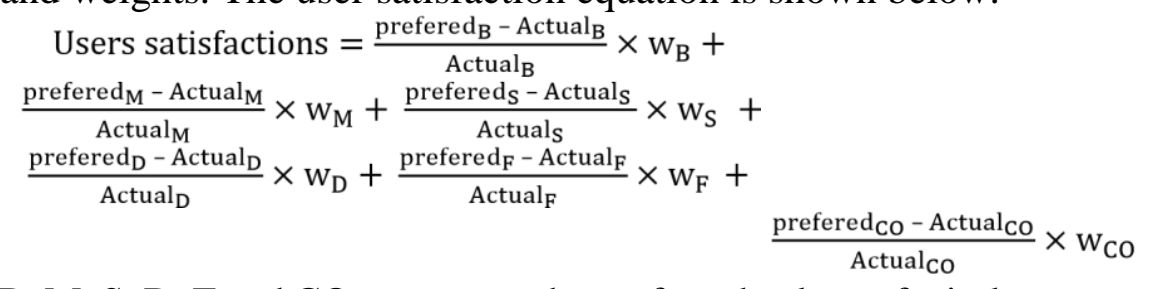

$\mathrm{B}, \mathrm{M}, \mathrm{S}, \mathrm{D}, \mathrm{F}$ and $\mathrm{CO}$ represents the preferred values of wireless network criteria which is being specified by MTs. The actual B, M, S, D, F and CO has characterized the actual values of wireless network criteria being in simulation, while $\mathrm{W}_{\mathrm{B}}, \mathrm{W}_{\mathrm{M}}, \mathrm{W}_{\mathrm{S}}, \mathrm{W}_{\mathrm{D}}, \mathrm{W}_{\mathrm{F}}$ and $\mathrm{W}_{\mathrm{CO}}$ indicates the weight of these criteria. 
2nd International Conference on Research in

\section{SCIENCE, ENGINEERING \& TECHNOLOGY}



8-10 November 2019

Figure 5. User's satisfactions depending on diverse cost



Figure 6. User's satisfaction depending on diverse bandwidth




2nd International Conference on Research in

\section{SCIENCE, ENGINEERING \& TECHNOLOGY}

Figure 7. User satisfaction depending on diverse security

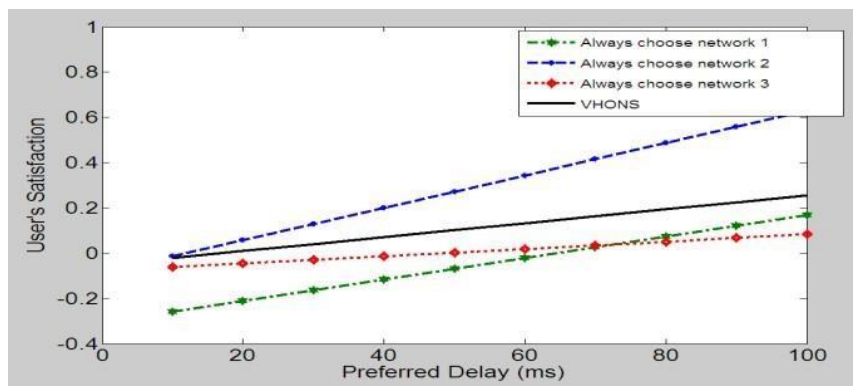

Figure 8. User satisfaction depending on diverse delay

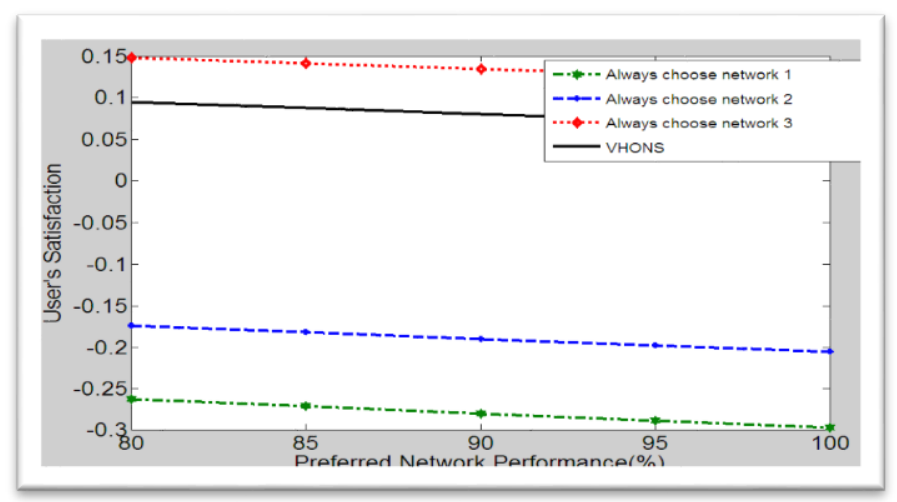

Figure 9. User satisfaction depending on different network performance

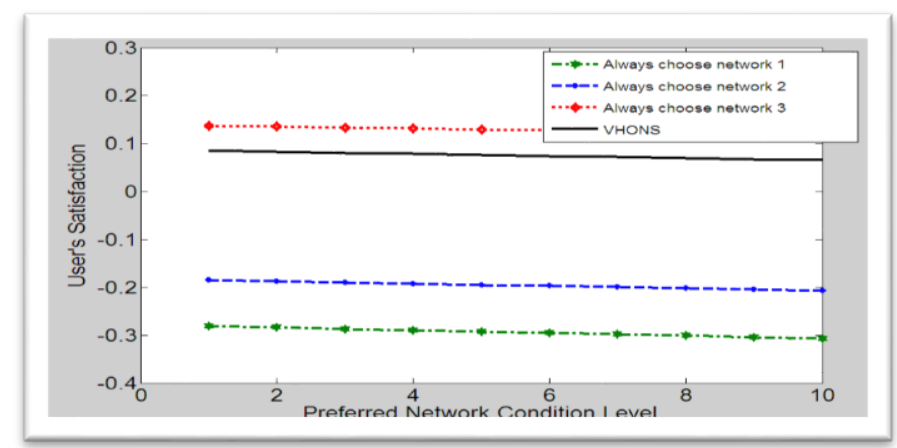


Figure 10. User satisfaction depending on different network condition

Figures 2, 3, 4, 5, 6, and 7 illustrate the user satisfaction rate which were generated by adopting the vertical handover network selection (VHONS) and also selecting the network numbered one, two and three consistently. In all these figures, the value for $\mathrm{P}_{\mathbf{w}}$ of MT is specified as $100 \%$.

Additional to these, In Figure 2, the preferred $\mathrm{B}$ and preferreds are specified as unchanged values of 500 kilobytes per second and 3, but the preferred delay, network performance and network condition are set to fixed values such as $(55,90,4)$. Figure 2 illustrating the result shows that the user's satisfaction was also identified according to diverse values of preferred cost as (prefered $\mathrm{d}_{\mathrm{M}}$ ) specified as 1:10. In that order, the user satisfaction was identified according to diverse values of preferred cost as preferre $d_{M}$, preferred delay as prefered $\mathrm{D}_{\mathrm{D}}$, preferred network performance as preferred $\mathrm{F}_{\mathrm{F}}$ and preferred network condition as preferred $\mathrm{C}_{\mathrm{CO}}$. The maximum user satisfaction was accomplished by using the VHONS method, and it did not take into account the budget values being specified by the end users.

The results in figure 3, show that the user's satisfaction was identified according to different

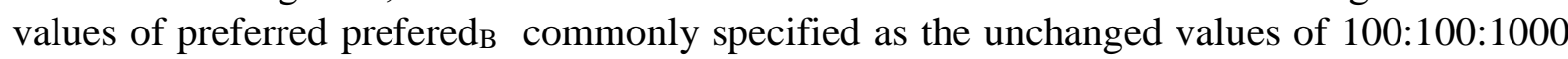
kilobytes per second. The result has also shown that in Figure 4, User satisfaction had been identified according to the diverse values of prefered $\mathrm{s}_{\mathrm{s}}$ specified as unchanged values of 1:10 level. Nonetheless, the result shown in Figure 5 suggests that the user's satisfaction was identified according to the diverse values of prefered $d_{D}$ specified as fixed values of 10:10:100 ms.

Furthermore, based on the result in figure 6, it shows that the user's satisfaction was identified

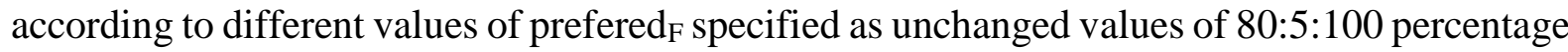
$(\%)$. Besides, the result in figure 7 demonstrates that the user's satisfaction was identified according to different values of prefered ${ }_{\mathrm{CO}}$ specified as unchanged values of 1:10 scale in level Generally, the results signify that the vertical handover network selection method (VHONS) can maximize the user's satisfaction and has helped its budget, which is specified by the end users, and also the fact that the method can handle other requirements.

In the nutshell, the evaluation of the performance for the proposed VHONS method has been shown. During the simulation experiment using the MATLAB software, it has been observed and demonstrated that the vertical handover network selection method is able to improve user satisfaction which relies on different values of bandwidth, security cost, delay, network performance and network condition parameters. 


\section{CONCLUSION}

In conclusion of this article, we have introduced a method called vertical

handover

network selection (VHONS), which has adopted the cost function method. It also used to select the network which has the lowest cost for handover. It includes two approaches which are the WD approach and cost factor calculation approach. The cost factor of the candidate wireless networks were evaluated and calculated by implementing the cost function method. The wireless access network with the low cost being able to be chosen as the handover wireless network target. The weights for several criteria being produced depends on user preferences and power of the MTs. Hence, the performance evaluation of proposed methods being showed. During the experiments in the MATLAB, it demonstrated that VHONS technique being able to improve and increase a level of user satisfaction with selecting a best wireless network as the handover target between several candidates of the wireless networks. This is done by applying a comparison with the other algorithms, which has chosen single access wireless network. 


\section{REFERENCES}

[1] A. States, S. Africa, C. Rica, R. Federation, S. Africa, I. T. U. W. Telecommunication, I. C. T. I. Database, I. T. Union, and A. R. Reserved, "Key statistical highlights : ITU data release June 2012," no. June, pp. 2011-2012, 2012

A. Dutta, S. Das, D. Famolari, Y. Ohba, K. Taniuchi, V. Fajardo, R. M. Lopez, T. Kodama, and H. Schulzrinne, "Seamless proactive handover across heterogeneous access networks," Wireless Personal Communications, vol. 43, no. 3, pp. 837-855, Jun. 2007.

K. Savitha and C. Chandrasekar, "Network Selection Using TOPSIS in Vertical Handover Decision Schemes for Heterogeneous Wireless Networks," vol. 8, no. 3, pp. 400-406, 2011.

M. Kassar, B. Kervella, and G. Pujolle, "An overview of vertical handover decision strategies in heterogeneous wireless networks," Computer Communications, vol. 31, no. 10, pp. 2607-2620, Jun. 2008.

a. Bhuvaneswari and E. George Dharma Prakash Raj, "An Overview of Vertical Handoff Decision Making Algorithms," International Journal of Computer Network and Information Security, vol. 4, no. 9, pp. 55-62, Aug. 2012.

VERTICAL HANDOVER DECISION," Journal of Theoretical and

Applied Information Technology, vol. 54, no. 2, pp. 339-345, 2013. [7] Pramod Goyal, and S. K. Saxena, "A Dynamic Decision Model for Vertical Handoffs across Heterogeneous Wireless Networks“. World Academy of Science, Engineering and Technology 412008.

[8] Sourav Dhar, Amitava Ray, Rabindranath Bera," Design and Simulation of Vertical Handover algorithm for Vehicular Communications", International Journal of Engineering Science and Technology Vol. 2(10), 2010, 5509-5525.

[9] N. P. Singh and B. Singh, "Improved Vertical Handover Decision Algorithm for UMTSWLAN 2 . Overview of Vertical Handover," vol. 4, no. 4, pp. 113-124, 2011.

[10] R. K. Singh, A. Asthana, A. Balyan, S. J. Gupta, and P. Kumar, "Vertical Handoffs in Fourth Generation Wireless Networks," no. 2, pp. 481-490, 2012.

[11] Gita Mahardhika, Mahamod Ismail, Rosdiadee Nordin "MULTI-

CRITERIA VERTICAL HANDOVER DECISION," Journal of Theoretical and Applied Information Technology vol. 54, no. 2, pp. 339-345, 2013.

[12] F. Zhu and J. McNair, "Optimizations for vertical handoff decision algorithms," 2004 IEEE Wireless Communications and Networking Conference (IEEE Cat. No.04TH8733), no. 3, pp. 867-872, 2004.

[13] F. Zhu and J. McNair, "Multiservice Vertical Handoff Decision Algorithms," EURASIP Journal on Wireless Communications and Networking, vol. 2006, pp. 1-13, 2006. 
2nd International Conference on Research in

SCIENCE, ENGINEERING \& TECHNOLOGY

[14] A. Hasswa, N. Nasser, and H. Hassanein. Tramcar: A contextaware cross-layer architecture for next generation heterogeneous wireless networks. In Proceedings of the 2006 IEEE

[15] International Conference on Communications (ICC'06), pages 240-245, Istanbul, Turkey, June 2006.

[16] R. Tawil, G. Pujolle, and O. Salazar, "A Vertical Handoff Decision Scheme in Heterogeneous Wireless Systems," VTC Spring 2008 - IEEE Vehicular Technology Conference, pp. 2626-2630, May 2008. 